\title{
El desarrollo humano en el Estado de México y el Distrito Federal, 1995-2000: Una lejana vecindad
}

\author{
FranCISCO JOSÉ ZAMUdio-SÁNCHEZ \\ Alejandro Corona-Ambriz \\ RubÉN GONZÁLEZ-Mireles*
}

\begin{abstract}
This paper analyses the evolution of the human development index between 1995 and 2000 for two states in Central Mexico: The State of Mexico and Distrito Federal. We follow the methodology proposed by the United Nations Development Programme which analyses the distribution of human development and is based on a concept of quality that measures the capacity of an entity to transform its income into development. The results show a noticeable bias in income towards Distrito Federal, which in turn denies any possible relationship of proximity among both parties.
\end{abstract}

Keywords: human development index, gender related development index, inequity index.

\section{Resumen}

En el presente artículo se analiza la evolución del índice de desarrollo humano entre 1995 y 2000 para dos entidades del centro de México: El Estado de México y el Distrito Federal. Para ello se sigue la metodología propuesta por el Programa de las Naciones Unidas para el Desarrollo (PNUD) que consiste en el análisis de la distribución del desarrollo humano y de un concepto de calidad que mide la capacidad de las entidades para transformar su ingreso en desarrollo. Los resultados permiten advertir notables sesgos en el ingreso a favor del Distrito Federal, lo cual niega toda posible relación de cercanía entre ambas entidades.

Palabras clave: índice de desarrollo humano, índice de desarrollo relativo al género, índice de inequidad.

*Universidad Autónoma Chapingo. Correos-e: fjzams@yahoo.com, ambrizcar@yahoo. com.mx, ruben_gmireles@yahoo.com.mx. 


\section{Introducción}

\subsection{Generalidades}

El concepto actual de desarrollo humano (DH) impulsado por Amartya Sen (Premio Nóbel de Economía, 1998) y otros, se deriva de la literatura sobre la desigualdad/pobreza y la preocupación no economista de que el ingreso no es el único criterio de desarrollo (Desai, 1991: 353). Lo primero concierne a la estructura del ingreso como un correctivo para el nivel y crecimiento del ingreso per cápita y lo segundo a que la gente a menudo valora metas que no se traducen del todo, o no inmediatamente, en mayor ingreso o cifras de crecimiento, como puede ser una mejor nutrición y servicios de salud, mayor acceso a la educación o mejores condiciones de trabajo.

La perspectiva impulsada por el Programa de las Naciones Unidas para el Desarrollo (PNUD) reconoce que, en todos los niveles del desarrollo, hay algunas capacidades y opciones que son esenciales para que las personas participen en la sociedad, contribuyan a ella y se desarrollen plenamente. Por tanto, el DH se entiende como un proceso cuyo objetivo es ampliar las capacidades de las personas así como su posible uso, ya que trata de propiciar un ambiente en torno a las mismas para que tengan un medio adecuado donde puedan desarrollarse potencialmente, es decir, ver a los seres humanos no sólo como los principales medios del desarrollo económico y social, capital humano, sino como los fines primarios del mismo (Anand y Sen, 2000: 83). El proceso consiste, al menos, en ampliar las opciones para tener una vida prolongada y saludable; conocimientos y acceso a los recursos necesarios para una vida digna. Esto último es quizá lo más difícil de medir en forma simple (Anand y Sen, 2000: 87) y por carencia de información se usa un indicador de ingreso (PNUD, 1990: 37). Alejandro Ramírez (1999: 16), a falta de información sobre el ingreso, propuso los servicios públicos como alternativa, lo cual es adecuado si se considera que a menudo el ingreso no está asociado con el estándar de vida, ya que la calidad de ésta puede variar mucho entre entidades geográficas con el mismo ingreso real y producto interno bruto per cápita (Anand y Sen, 2000: 84).

En el mismo tenor de la desigualdad en la distribución del ingreso está la preocupación por la desigualdad en el desarrollo entre hombres y mujeres, ya que si las crisis económicas ocasionan un deterioro en la vida de la gente, no menos cierto es que éste se presenta con mayor frecuencia y de forma más aguda 
entre las mujeres. Por ello se busca igualdad de derechos entre mujeres y hombres, que ellas sean consideradas como agentes y beneficiarias del cambio y que hombres y mujeres tengan iguales oportunidades en todos los aspectos (PNUD, 1995: 2). Así, una iniciativa de Naciones Unidas considera el desarrollo de las capacidades de las personas diferenciándolas por género, de manera que, aunque sólo se incluyan pocas dimensiones en la medición de éste, tal situación sea reconocida por quienes toman las decisiones en la elaboración de políticas sociales.

La inequidad que se observa en el DH es otra de las preocupaciones que motivan el análisis cuando se habla del bienestar de las personas. Con el fin de determinar la variación de la distribución del DH dentro de un Estado se requiere una medida de la desigualdad e inequidad con la que se da este desarrollo. Desigualdad e inequidad son dos conceptos relacionados, pero diferentes, que de manera recurrente se usan en el análisis del DH, por lo que conviene, aunque de forma breve, precisar las diferencias entre ambos. De acuerdo con López Arellano (2005: 4), cuando se habla de desigualdad socioeconómica se hace referencia a diferencias entre personas y grupos, así como a la apropiación desigual en términos económicos y sociales. Esto puede tener al menos tres interpretaciones extremas: primera, la desigualdad se explica y justifica por las capacidades y méritos de los distintos individuos; segunda, la desigualdad socioeconómica es producto de la organización social, de la producción colectiva, de la apropiación privada y de la distribución inequitativa de la riqueza; tercera, la desigualdad económica es el resultado del sistema de valores de cada sociedad, de los roles y posiciones que ocupan los individuos en ellas y del valor que una sociedad en particular asigna a esos roles. En esta lógica, en una sociedad que privilegia más la libertad de elección que la justicia distributiva, se propone la construcción de pisos de oportunidades iguales; mientras que en otra que otorga mayor importancia a la justicia distributiva se hará énfasis en la garantía de derechos para todos sus ciudadanos. Cuando se habla de inequidad se hace referencia a diferencias que se consideran injustas y evitables, lo cual nos lleva al campo de las valoraciones éticas y políticas. "No todas las diferencias o desigualdades son pertinentes a la inequidad: sólo aquéllas envueltas en problemas de injusticia que vayan en contra de las opciones que deben existir para el surgimiento y realización de todas las personas, o contra derechos inherentes a los aspectos vitales de la existencia humana; un trato desigual no siempre es inequitativo ni lo diferente es siempre injusto” (Molina, 2005: 2). 
Finalmente, es necesaria alguna medida del uso del ingreso. En la perspectiva del DH no sólo se valora cómo se consigue un bien sino las posibilidades que éste otorga. Se requiere valorar qué tanto del ingreso se traduce en opciones para el bienestar de las personas y, en la perspectiva de una escala municipal, los servicios públicos representan una estimación indirecta fundamental del desarrollo de las capacidades de las personas. Se sabe que los bienes y servicios exhiben tasas decrecientes frente al ingreso y por ello no es posible esperar que los incrementos en ingresos se traduzcan directamente en bienes y servicios. Además, no todos los municipios con un mismo ingreso traducen iguales tasas a servicios públicos, esto depende de las prioridades que determinen los funcionarios en turno. De este modo, conocer en promedio cuánto del ingreso en México, descontados los rendimientos decrecientes, se transforma en opciones que permitan una vivienda digna o los servicios básicos para la realización de las diferentes actividades económicas, es de vital importancia para determinar si el aumento del ingreso tiene su correspondiente esperado en el desarrollo. También, para cada ingreso específico, saber cuál es el desarrollo esperado en el municipio posibilita la comparación de éstos en cuanto a los logros alcanzados en la expansión de sus capacidades.

\subsection{Indices $y$ estimaciones}

En el presente trabajo se analiza el grado de DH en el Estado de México (México) y el Distrito Federal (DF) usando el índice de desarrollo humano con producto interno bruto per cápita (IDHP), el índice de desarrollo humano relativo al género (IDG) y el índice de desarrollo humano con servicios (IDHS). El IDHP se compone de tres factores: salud, medida por la esperanza de vida al nacer; educación, medida por la alfabetización tanto infantil como de adultos; e ingreso, medido por el producto interno bruto per cápita (PIBP) ${ }^{1}$ en dólares PPA $^{2}$ (PNUD, 1990: 38). El IDHS, a diferen-

\footnotetext{
${ }^{1}$ Método para transformar el PIBP en dólares PPA a pesos de 1993. El PIBP en dólares PPA se multiplica por el factor de conversión $($ PPA 2000) $=6.14537906646729$. El valor obtenido se divide por $\mathrm{k}=3.68363804420555$ para obtener pesos de 1993.

${ }^{2}$ PPA (paridad de poder adquisitivo) en dólares. Las tasas de PPA permiten determinar el número de unidades de la moneda de un país necesarias para adquirir la misma canasta representativa de bienes y servicios que un dólar de Estados Unidos adquiriría en tal país. Las paridades de poder adquisitivo también pueden expresarse en otras monedas o en derechos especiales de giro (DEG). La PPA permite comparar el nivel real de los precios entre países, de la misma manera que los índices convencionales de precios permiten hacer comparaciones del valor real en el tiempo; de otra manera, el tipo de cambio normal puede sobrevalorar o subvalorar el poder adquisitivo (PNUD, 2001: 254).
} 
cia del IDHP, considera como recursos necesarios para una vida digna a tres servicios públicos: agua entubada, drenaje y electricidad (Ramírez, 1999: 16). Por su lado, el IDG mide los mismos componentes que el IDHP pero refleja las diferencias de desarrollo entre hombres y mujeres (PNUD, 1995: 73). Estos índices son importantes porque hacen notar las carencias y privaciones que sufre la población de un país, estado, municipio o región en su desarrollo. En este estudio también se analiza el grado de inequidad en el DH en las dos entidades empleando el índice de inequidad del desarrollo humano con PIBP (InQIDHP), que se define como uno menos el índice de Gini (InG) aplicado al IDHP (Medina, 2001). Además, por medio de la técnica de curvas de calidad se estudia la capacidad de las entidades y sus municipios para traducir el ingreso en DH (Zamudio, 1997; Bojorges, 2000; Pérez, 2001).

La memoria técnica y los cálculos de cada uno de los índices, elaborados por el Departamento de Estadística, Matemática y Cómputo (DEMYC) de la Universidad Autónoma Chapingo (UACh), aparecen en el sitio de la red: http:/www.chapingo.mx/dicifo/ demyc/idh/index.php

\subsection{Condiciones generales del desarrollo humano en México}

Las características generales del DH en México, considerando como tercer factor al PIBP, muestran que el país, en el 2000, estaba cerca de alcanzar la categoría alta de acuerdo con el PNUD, lo que indica las condiciones mínimas generadas para potenciarlo. En la clasificación mundial de 174 países ocupó el lugar 54 por debajo de Latvia y antes de Cuba (PNUD, 2002:150). Los extremos del DH en México están en el Distrito Federal (similar a Barbados y Brunei Darussalam, PNUd, 2002: 149) y Chiapas (comparable con Algeria y República de Moldavia, PNUD, 2002: 151). La salud es el factor mejor distribuido entre los estados, de 71.14 a 76.64 años, lo que señala una cierta equidad en la longevidad de los habitantes y oportunidades de alcanzar algunas metas y deseos. El ingreso, medido por el producto interno bruto per cápita (PIBP), es el factor que muestra la mayor heterogeneidad, de modo que el DF tiene un ingreso 6.14 veces mayor que el de Oaxaca y con ello más oportunidades para una mejor vida. La inequidad de este factor determina en mucho la divergencia en las opciones de desarrollo de los mexicanos, ya que el indicador del ingreso tiene una alta correlación simple con la del de educación (0.7106), aunque ésta es muy baja comparada con el indica- 
dor de salud (0.0522). Al considerar el ingreso y la educación, en el indicador de desarrollo se tienen dos factores cuya posibilidad de duplicar la información, por su alta correlación, es muy probable. Si se agrega que la distribución del ingreso se concentra en sólo parte de la población, ocurrirá otro tanto con la educación, y así el ingreso determinará preponderantemente los valores del DH a través de su indicador mostrando las divergencias o contrastes en las posibilidades que tienen los mexicanos para potenciar su desarrollo. Por otro lado, la correlación entre salud y educación $(0.1663)$ nos indica la marginal independencia del factor salud en el DH del país, y así se tiene que la distribución de las opciones que prolongan la vida no sólo es la más uniforme sino que ha proporcionado a los habitantes una cierta independencia con respecto a su educación e ingreso. Esta ventaja comparativa está amenazada por el abandono que ha sufrido el factor salud en los últimos años, el estrés a que está sometida la población de las grandes urbes y la violencia que engendran los giros negros en la economía.

Los contrastes señalados, con algunas singularidades y pocas excepciones, se dan entre:

- Las regiones norte, centro y sur de la República Mexicana, sobre todo en las dos primeras. La vecindad de los estados norteños con los Estados Unidos, por un lado, y el grado de industrialización, comercio y servicios en el centro, por otro, explican las disparidades.

- Los estados del norte muestran una menor dispersión del DH que los del centro y el sur. La fragmentación de los estados (por ejemplo, Oaxaca con 570 municipios), sus altos índices de población indígena, migración y actividades primarias se asocian con el bajo desarrollo de las entidades federativas del centro y sur del país.

- En los municipios con menores ingresos la inequidad es mayor.

Si en lugar del PIBP se utilizan los servicios públicos en la medición del DH, se presenta una situación análoga.

Respecto del desarrollo relativo al género existen diferencias en las oportunidades que tienen hombres y mujeres en México. En general la salud es mejor en las mujeres (76.24-71.50 años) mientras que el ingreso le es favorable a los hombres $(8,296.58$ 22,289.30 pesos de 1993). En educación la situación es más equilibrada, pero en alfabetización adulta existe un sesgo positivo 
hacia los hombres (92.47-88.60\%) y en alfabetización infantil lo hay hacia las mujeres, aunque en menor medida (87.77-86.80\%). Aun siendo favorable el factor salud en las mujeres, la abismal diferencia en el PIBP ocasiona, en la medición del DH, una situación de inequidad para las mujeres. Sin duda, esta comparación es inapropiada porque mientras la salud es una dimensión directa del DH, no lo es así para el PIBP; no obstante, como dimensiones del desarrollo que se integran en un mismo indicador, la comparación de géneros se tiene que hacer como tal. Lo anterior indica que aun con una vida más longeva, las mujeres no cuentan con los mismos recursos que los hombres para alcanzar su bienestar. La entidad con menor inequidad de género es el DF (4.96 años y 0.34\% de alfabetización infantil a favor de las mujeres; $219.22 \%$ más PIBP y $2.32 \%$ de alfabetización adulta a favor de los hombres), en una condición similar a la de Brunei Darussalam (PNUD, 2002: 222), en el otro extremo está, de nuevo, Chiapas (3.7 años a favor de las mujeres; $300 \%$ más PIBP, 0.79\% de alfabetización infantil y $12.23 \%$ de alfabetización adulta a favor de los hombres), como en el caso de El Salvador (PNUD, 2002: 224). Algunas asociaciones recurrentes entre la inequidad de género y los factores sociales y económicos son los siguientes:

- A mayor pobreza.

- Entre grupos indígenas.

- A mayor analfabetismo.

Éstas no son las únicas relaciones perversas pero señalan los característicos círculos viciosos correlacionados con los roles de importancia que se da a varios atributos deseables o indeseables en nuestra sociedad. La disparidad de ingreso es el componente que determina la disparidad de DH entre entidades federativas $y$, dentro de cada una de ellas, también es el que determina las diferencias más significativas entre hombres y mujeres.

Por otro lado, la distribución del DH dentro de los estados del país está en consonancia con los problemas mencionados en el bienestar de las personas; en los estados donde se localizan los DH más bajos se tienen las dispersiones más altas del mismo entre los municipios que los conforman. Así, en un mismo estado se encuentran municipios con alto DH y otros con desarrollo bajo, cuyas distancias indican una distribución muy amplia del mismo, aun cuando la condición deseable es que todas las partes del estado alcancen desarrollos similares. Los estados que muestran mayores dispersiones en el DH de sus municipios son, con fre- 
cuencia, los que tienen un gran números de ellos, por lo que, entre otros aspectos, Oaxaca (570 municipios) es el que tiene la peor distribución de esta condición deseable. Otros en situación similar son Chiapas (119), Hidalgo (84), Guerrero (76), Puebla (217) y Veracruz (210). Siguiendo esta premisa, los estados con pocos municipios gozan de una distribución concentrada en su DH, como en los casos de Baja California (5) y Aguascalientes (11). Algunas entidades, cuyo número de municipios es considerable, poseen la cualidad de tener una aceptable distribución de DH, como Chihuahua (67) y Jalisco (124). Además de la dificultad que representa la administración de muchos municipios dentro de un estado en las opciones con que cuente para un buen desarrollo, se tienen las que se asocian con las condiciones geográficas y la complicación que acarrea el no tener suficientes vías de comunicación, la distancia de las cabeceras municipales con la capital del estado, el tamaño de la población que determina en cierta medida la conveniencia de los servicios públicos y la importancia que los gobiernos le asignan, el ingreso que representan proporcionalmente para el estado, así como otros aspectos que se ponderan en la asignación de recursos para políticas de desarrollo social. Las dificultades aquí expresadas para tener un DH igualitario entre los municipios de cada estado indican la necesidad de planes de desarrollo con criterios distintos a los de la eficiencia económica y utilitarista de quienes no sólo ven a la gente como medios y promotores del desarrollo económico sino, también, como los depositarios finales del DH.

En el concepto de calidad de las entidades del país, donde se trata de calificar cómo se traduce su ingreso en DH, asignando, en un determinado ingreso base, una mejor calidad a aquéllas que presentan un DH mayor (medido por el IDHS), se observa que no son las entidades con mayores ingresos las que traducen este ingreso (llevado al ingreso base de comparación) en mejores opciones de crecimiento para sus pobladores. Los estados con las mejores calidades son Tlaxcala (PIBP $=\$ 4,977.57$ dólares PPA, IDHS $=0.85552)$, Nayarit $(\$ 5,377.24,0.84714)$ y Zacatecas $(\$ 5,010.04,0.83617)$. El cuarto lugar lo ocupa el Estado de México $(\$ 7,256.96,0.85674)$. Las calidades más bajas se observan en Campeche (\$13,819.89, 0.80590), DF (\$23,319.09, $0.88764)$ y Querétaro $(\$ 10,842.36,0.82891)$. Aquí se observa que no es necesario un gran ingreso para un DH alto que proporcione a la gente las condiciones mínimas para potenciar sus capacidades. Los estados con mejor calidad tienen aproximadamente la mitad del ingreso de aquéllos con las calidades más 
bajas y, sin embargo, sus mediciones de desarrollo son equiparables. Anand y Sen (2000) señalan que el límite superior del ingreso, que Naciones Unidas considera que incide totalmente sobre el DH, es de \$5,120.00 dólares PPA, de modo que ingresos superiores a esta cota se transforman en DH con rendimientos decrecientes. Para el caso de México este límite se ajusta apropiadamente. Sin el propósito de minimizar lo anterior por su correspondencia con la teoría del DH, se debe apuntar que esas diferencias de ingreso tienen efectos sobre las múltiples opciones que determinan la potenciación de las capacidades humanas, como pueden ser opciones de mejor educación, descanso, paseo, vivienda, u otras de orden superior como la libertad, los derechos humanos o el derecho a la información, por lo que diferencias de tal magnitud favorables a los de mayor ingreso, con DH equiparables a los de escasos ingresos, nos indican una baja calidad en la gestión de su transformación.

\subsection{Las entidades bajo análisis}

En este contexto general, la situación del Estado de México y el DF tiene disparidades como las que se encuentran entre las regiones norte y sur del país. Además, los papeles desempeñados por estas entidades en su desarrollo histórico contribuyen en las desigualdades: México en su papel de proveedor de mano de obra y el DF en el de proveedor de trabajo por su desarrollo industrial, comercial y de servicios, determinan una relación de dependencia desfavorable para el primero.

De ahí que las principales hipótesis de este trabajo sean: a) las diferencias entre estas entidades, así como las diferencias al interior de ellas debilitan la aspiraciones del $\mathrm{DH} ; b$ ) el ingreso determina las diferencias entre ambas pues afecta directamente aspectos como la educación y otros servicios, el bienestar familiar y social, la infraestructura general, etcétera; c) en el Estado de México, además de su exiguo ingreso, se tiene un sistema educativo desequilibrado y condiciones para la esperanza de vida por debajo del promedio nacional; $\mathrm{y} d$ ) en el DF el factor salud presenta un deterioro, consecuencia de sus difíciles condiciones de vida, y ciertas delegaciones lo padecen aún más.

\section{Antecedentes}

En la Universidad Autónoma Chapingo (UACh), el DEMYC conduce un programa de investigación sobre DH en México desde el inicio 
del año 2000. Los resultados que constituyen el I Informe sobre Desarrollo Humano en México 1995 a escala municipal, con los datos del xi Censo de Población y Vivienda 1990 y el I Conteo de Población y Vivienda 1995, se ubicaron en el programa arriba mencionado en diciembre del mismo año. Posteriormente, en la primera mitad de 2002, se agregaron los resultados del II Informe sobre Desarrollo Humano en México 2000 con los datos del XII Censo de Población y Vivienda 2000 y el I Conteo de Población y Vivienda 1995.

Otros informes en México a escala municipal y para todo el país utilizan la información del XII Censo 2000 y se difundieron a partir del año 2002. Primero, uno del Consejo Nacional de Población (Conapo) y después otro del PNUD, de modo que no establecen ninguna tendencia.

Para el Estado de México y el Distrito Federal es el primer estudio comparativo entre 1995 y 2000 donde se analiza el grado de desarrollo alcanzado y la tendencia en el quinquenio de estas entidades y sus partes.

\section{Resultados}

\subsection{Estado de México}

\subsubsection{Descripción breve del Estado de México}

El Estado de México representa el 1.1\% de la superficie del país y ocupa el lugar 25 (de las 32 entidades) en extensión territorial. Está dividido en 125 municipios y la capital es Toluca de Lerdo. Colinda al norte con los estados de Querétaro de Arteaga e Hidalgo; al este con Hidalgo, Tlaxcala y Puebla; al sur con Morelos y Guerrero; y al oeste con Guerrero y Michoacán de Ocampo. Rodea al DF al norte, este y oeste (INAFED, 2001).

Desde 1985 es el estado más poblado del país, en 1995 tenía 11'707,964 habitantes y para el 2000, 13'096,686, de los cuales $2.8 \%$ eran indígenas (INEGI, 2000a). Un problema serio se genera por el hecho de que la distribución de la población no es homogénea, Ecatepec y Nezahualcóyotl cuentan con más de un millón de habitantes, mientras que Papalotla y Zacazonapan no llegan a cinco mil. Tal polarización hace del Estado de México una entidad con muchos problemas demográficos.

En los últimos años la actividad económica más importante del estado es el sector terciario (servicios, comercio, restaurantes y hoteles, principalmente), seguida por el sector secundario 
(construcción, industria manufacturera y minera). La industria manufacturera ha sido la base del crecimiento económico del estado y, por su cercanía con el DF, ha logrado un desarrollo que lo coloca como la segunda entidad más importante del país, en términos económicos (Aregional, 2001).

\subsubsection{Análisis del desarrollo humano en el Estado de México}

\subsubsection{1 Índice de desarrollo humano con PIB per cápita (IDHP)}

En el año 2000 el Estado de México obtuvo un IDHP de 0.78895 (cuadro 1) que, de acuerdo con el criterio del PNUD, ${ }^{3}$ se clasifica como DH medio. Ocupa la decimoctava posición a escala nacional, distante del DF que ocupa la primera posición (0.86258). Internacionalmente, es similar al obtenido por los países centroamericanos de Belice y Panamá y a la nación asiática de Malasia (PNUD, 2002: 150).

Los incrementos de los diversos índices en el quinquenio se midieron con respecto a lo que les faltaba para alcanzar el máximo valor de 1 , que es la brecha que habrá de transitarse para alcanzar las condiciones mínimas de desarrollo. Se presenta, con propósitos comparativos, el incremento del PIBP respecto del valor que tenía en 1995. La diferencia, en porcentaje, de estos dos incrementos, uno [InPIBP(2000)-InPIBP(1995)/1-InPIBP(1995)] ×100 y el otro [PIBP(2000)-PIBP(1995)/PIBP(1995)] $\times 100$, se debe a las escalas de ambos y a que en el Inpibp ya se consideró que no todo el ingreso se ocupa en DH.

En el periodo 1995-2000 el IDHP tuvo un incremento de 10.22\%. El crecimiento en los componentes del desarrollo es semejante al del promedio nacional, excepto en alfabetización infantil donde tuvo un aumento significativamente menor en 2.54\%. México tiene la segunda mejor tasa de alfabetización infantil, sólo debajo de Nuevo León, a pesar de ello, el que 7.4 de cada 100 niños entre 6 y 14 años no sepan leer ni escribir genera a un grupo importante de personas que en los próximos 20 años enfrentará condiciones precarias para incorporarse a la vida económica y social, además de estar privada de la posibilidad de hacer uso de otras opciones para su desarrollo. El avance del IDHP, está en la dirección del crecimiento económico de la enti-

${ }^{3}$ El PNUD clasifica un índice, excepto el IDG, como bajo cuando su valor es menor a 0.5 , medio cuando su valor es mayor o igual a 0.5 y menor a 0.8 , y alto cuando su valor es mayor o igual a 0.8 . 
dad, reflejo de algunas transformaciones que ha sufrido la estructura económica de 1993 al 2000. Los sectores que aumentaron su contribución a la economía estatal fueron la industria manufacturera y el transporte, así como el almacenaje y las comunicaciones; los cuales se incrementaron en $2.19 \%$ y $0.9 \%$, respectivamente (Aregional, 2001).

De acuerdo con el cuadro 1, al comparar el IDHP nacional con el estatal se observa un rezago de este último ocasionado básicamente por el ingreso superior que tiene el país, aun cuando el índice educativo favorece al Estado de México.

\section{Cuadro 1}

Comparación entre el IDHP y el IDHS (1995-2000) del Estado de México y el país

\begin{tabular}{|c|c|c|c|c|c|c|}
\hline \multirow[t]{2}{*}{ Indicadores } & \multicolumn{3}{|c|}{ Entidad } & \multicolumn{3}{|c|}{ Nacional } \\
\hline & 1995 & 2000 & $\begin{array}{l}\text { Incremento } \\
(\%)\end{array}$ & o 1995 & 2000 & $\begin{array}{c}\text { Incremento } \\
(\%)\end{array}$ \\
\hline $\begin{array}{l}\text { Índice de esperanza } \\
\text { de vida* al nacer }\end{array}$ & 0.69050 & 0.71950 & 9.36 & 0.70967 & 0.73133 & 7.46 \\
\hline (InEsp) & $\begin{array}{l}71.43 \\
\text { Años }\end{array}$ & $\begin{array}{l}73.17 \\
\text { Años }\end{array}$ & & $\begin{array}{l}72.58 \\
\text { Años }\end{array}$ & $\begin{array}{l}73.88 \\
\text { Años }\end{array}$ & \\
\hline $\begin{array}{l}\text { Índice de } \\
\text { matriculación infantil } \\
\text { (InMat) }\end{array}$ & 0.92076 & 0.92602 & 6.64 & 0.85994 & 0.87280 & 9.18 \\
\hline $\begin{array}{l}\text { Índice de } \\
\text { alfabetización } \\
\text { de adultos (InAlf) }\end{array}$ & 0.92757 & 0.93535 & 10.74 & 0.89258 & 0.90451 & 11.10 \\
\hline Índice producto & 0.67894 & 0.71511 & 11.27 & 0.71931 & 0.75229 & 11.75 \\
\hline $\begin{array}{l}\text { interno bruto per } \\
\text { cápita }\end{array}$ & $\begin{array}{l}5,843.00 \\
\text { dólares }\end{array}$ & $\begin{array}{l}\text { 7,256.96 } \\
\text { dólares }\end{array}$ & 24.19 & $\begin{array}{c}\text { 7,441.89 } \\
\text { dólares }\end{array}$ & $\begin{array}{l}\text { 9,067.94 } \\
\text { dólares }\end{array}$ & 21.85 \\
\hline (InPIBP) & PPA & PPA & & PPA & PPA & \\
\hline IDHP & 0.76491 & 0.78895 & 10.22 & 0.77022 & 0.79252 & 9.70 \\
\hline $\begin{array}{l}\text { Índice de agua } \\
\text { (InAgu) }\end{array}$ & 0.91517 & 0.92837 & 15.56 & 0.84580 & 0.87832 & 21.09 \\
\hline $\begin{array}{l}\text { Índice de drenaje } \\
\text { (InDre) }\end{array}$ & 0.83416 & 0.84926 & 9.10 & 0.72401 & 0.76178 & 13.68 \\
\hline $\begin{array}{l}\text { Índice de electricidad } \\
\text { (InEle) }\end{array}$ & 0.97643 & 0.97778 & 5.73 & 0.92797 & 0.94801 & 27.82 \\
\hline IDHS & 0.84146 & 0.85673 & 9.63 & 0.80798 & 0.82932 & 11.11 \\
\hline
\end{tabular}

* Las estimaciones de la esperanza de vida y PIBP son precisas en poblaciones mayores a 50,000 habitantes, de otro modo, tendrán fluctuaciones considerables.

Fuente: Cálculos propios con datos del IneGr. Conteo de Población y Vivienda 1995 (Conteo 1995), XI Censo General de Población y Vivienda 1990 (XI Censo 1990), XII Censo General de Población y Vivienda 2000 (XII Censo 2000), Banco de Información Económica (BIE) y Sistema Municipal de Base de Datos (Simbad).

El mayor incremento en esperanza de vida se explica por el atraso que la entidad tenía en 1995. En el 2000 los derechohabientes representaron $39.68 \%$ de la población total, dicho por- 
centaje era el decimoctavo más elevado del país e indica que una parte significativa de la población no tenía acceso a los servicios de salud. La esperanza de vida (73.17 años) es de las más bajas del país (lugar 27). Si se observa la esperanza de vida promedio de esta entidad a los 9, 19, 29, 39 y 49 años, su mejor lugar en la clasificación nacional es el 24. Es decir, no sólo la tasa de mortalidad infantil es alta respecto de otros estados, sino que permanecen altas conforme envejece la población, señalando una situación adversa recurrente en el factor salud.

Con respecto a 1995, se dio un avance importante en la dotación de opciones mínimas para el desarrollo de la población, debido a que en ese año 119 municipios tenían un DH medio (91.94\% de la población), y sólo tres municipios tenían un DH alto. Durante el periodo $1995-2000,45.35 \%$ de la población con DH medio en 1995 pasó a DH alto.

En el 2000 se presentaron diferencias muy marcadas en la entidad. Es decir, los municipios con IDHP más alto fueron: Coacalco de Berriozábal (0.82968), Jaltenco (0.82683), Cuautitlán Izcalli (0.82478) y Atizapán de Zaragoza (0.82066); su localización cercana con el DF les permite tener una economía muy activa que se traduce en los mejores ingresos del estado. De modo implícito, también cuentan con los mejores niveles educativos. En el otro extremo, los municipios con IDHP más bajo fueron: Donato Guerra (0.64436), Villa Victoria (0.64700), Sultepec (0.64782) y San Felipe del Progreso (0.64952). En contraste con los municipios anteriores, estos colindan con los estados de Michoacán de Ocampo y Guerrero; su principal actividad económica se basa en el sector primario y el porcentaje de población indígena es significativa. Al igual que en todo el país, desarrollo bajo, sector primario y población indígena son características que se presentan simultáneamente con mucha frecuencia en el estado.

Es importante mencionar que los municipios con los mayores cambios en este indicador de desarrollo durante el periodo fueron Ixtapaluca, Valle de Chalco Solidaridad y Zacazonapan, con 23.91\%, $20.51 \%$ y $20.26 \%$, respectivamente. El aumento del IDHP se debe en gran medida al incremento en el PIBP y la esperanza de vida.

Más de la mitad de la población mexiquense tiene condiciones de DH similares y dispone de las condiciones mínimas necesarias para su desarrollo, sin embargo, la mayoría de esta población radica en municipios que colindan con el DF. La distribución de opciones de desarrollo en la entidad no es equitativa ya que los servicios de salud, educación y empleo, se concentran en pequeñas regiones (urbano-metropolitano) con grandes poblacio- 
nes. En contraposición, el rezago en la región rural es preocupante, por lo que una planeación en las políticas sociales que revierta esta polarización permitirá un desarrollo equilibrado que sea socialmente sustentable.

\subsubsection{2 Índice de desarrollo humano con servicios (IDHS)}

El IDHS estima el desarrollo sustituyendo el bienestar dado por el PIBP por el proporcionado por los tres servicios básicos: agua entubada, electricidad y drenaje. Este cambio es congruente con las ideas de Amartya Sen (Anand y Sen, 2000: 86), ya que el PIBP es un instrumento indirecto del acceso a los recursos para disfrutar de un estándar de vida decente, no así los servicios de vivienda que directamente inciden sobre ella. Además, los tres servicios públicos señalados ofrecen una medición de la parte del ingreso que se destina al DH.

En el año 2000, el Estado de México se clasificó en la categoría de DH alto (cuadro 1) como la octava entidad del país con mejor IDHS, por arriba de Baja California Sur y abajo de Quintana Roo. La discrepancia en México de estos dos indicadores de desarrollo, IDHP e IDHS, se debe a que su ingreso es bajo en relación con los servicios públicos con que cuenta. Se puede decir que a pesar del bajo ingreso, parte significativa del estado se traduce en servicios para la población y, desde la perspectiva de la teoría del Estado, puede interpretarse como una manifestación de la intervención de éste.

En el periodo 1995-2000, el IDHS del estado logró un incremento menor al nacional en $1.48 \%$, sin embargo, los avances en la provisión de agua, drenaje y energía eléctrica a los habitantes corresponde con el crecimiento de su ingreso. En el año 2000 los servicios públicos de México sobresalieron de los de la mayoría de las demás entidades federativas; es decir, ocupó la decimo segunda posición con el mejor InAgu y sexta en el Indre e InEle. Durante el periodo, la entidad pudo mantener sus indicadores, a pesar de ser el estado con mayor inmigración, aumentando con ello la población a la que se debe dotar de estos servicios. Aunque el índice de drenaje fue el más bajo de la entidad, no es exclusivo del Estado de México, pues en todos los estados del país, excepto el DF donde los tres servicios tienen la misma cobertura y Tabasco donde hay más carencia de agua, es el servicio con mayor rezago. De hecho, los tres servicios tienen mayor cobertura en México que en el resto del país, de modo que las condiciones de vivienda ofrecen mejores oportunidades a los mexiquenses para una vida 
adecuada. Al cambiar la dimensión del ingreso del IDHP, desfavorable a México, por la de los servicios en el IDHs, favorable a la entidad, la situación de desarrollo para el estado luce muy diferente y sólo la dimensión de la esperanza de vida se encuentra por abajo, pero cerca del promedio nacional. Desde 1995 la mayoría de la población se encontraba en la categoría de DH alto. En el quinquenio, 11 municipios con desarrollo medio se incorporaron a la clasificación alta. En el año 2000, de los 125 municipios que integran al Estado de México, 39 obtuvieron un DH medio y 83 presentaron un DH alto (87.64\% de la población estatal).

La población de la entidad (87.64\%) que dispone de las condiciones mínimas necesarias para llevar una vida digna, considerando como tercer factor los servicios, está, como era de esperarse, en los municipios que colindan con la ciudad de México: Coacalco de Berriozábal que obtuvo el mayor IDHs (0.91188) seguido por Cuautitlán Izcalli (0.90415) y Atizapán de Zaragoza (0.90288). En oposición, los municipios de Villa Victoria (0.60366), Donato Guerra (0.62712) y San Felipe del Progreso (0.62978) presentaron el IDHS más bajo, posición que coincide con la dada por el IDHP. Estos municipios se ubican en la parte noroeste de la entidad y su orografía se caracteriza por sistemas montañosos de media altura, lo que provoca, en cierta forma, la carencia de los servicios básicos y con ello la escasez de otras oportunidades que permitan a sus pobladores un mayor bienestar.

\subsubsection{3 Índice de desarrollo humano relativo al género (IDG)}

El índice de DH relativo al género (IDG) mide el progreso en las mismas dimensiones y utiliza iguales indicadores que el IDHP pero refleja las desigualdades en las opciones de desarrollo entre el hombre y la mujer. Mientras mayor sea la disparidad de género en el DH, más será la diferencia entre el IDHP y el IDG de un país, estado o municipio (PNUD, 2001: 14). No sólo es posible que se presenten diferencias en las opciones para el desarrollo de las capacidades entre dos grupos de personas, también se pueden dar en las oportunidades que se tengan para hacer uso de las capacidades desarrolladas, aunque aquí sólo se hablará de las primeras.

El IDG del Estado de México en 1995 fue 2.47\% inferior a su IDHP, lo que refleja la desigualdad ${ }^{4}$ de oportunidades que enfrentan, en general, las mujeres en relación con los hombres. Para el $\times 100$.

${ }^{4} \mathrm{La}$ forma como se mide la desigualdad de género es la siguiente: (|IDHP-IDG|/IDHP) 


\section{Cuadro 2 \\ Desarrollo humano en el Estado de México, 2000}

\begin{tabular}{lccc}
\hline & \multicolumn{2}{c}{ Índice } & Desigualdad \\
& 1995 & 2000 & $(\%)$ \\
\hline PIB per cápita (IDHP) & 0.76491 & 0.78895 & 2.47 \\
Relativo al género (IDG) & 0.74601 & 0.77771 & 1.42 \\
\hline
\end{tabular}

Fuente: Cálculos propios con datos del INEGI. Conteo 1995, XI Censo 1990, XII Censo 2000, BIE y Simbad.

2000 esta diferencia se redujo a 1.42\% (cuadro 2). Así, la desigualdad de género disminuyó cerca de la mitad (42\%), pero no fue suficiente para ubicarse por abajo de 1\%, cota superior para declarar que no existen diferencias significativas de género. ${ }^{5}$

La dimensión más significativa en la desigualdad de género está en los recursos para una vida decente, dada por la gran diferencia entre el ingreso del hombre y la mujer; en el 2000 el ingreso de los hombres era de $\$ 10,820.11$ dólares PPA y el de las mujeres de $\$ 3,844.16$ dólares PPA, es decir, 2.81 veces mayor. La productividad del sector terciario, en general, es mayor a la de los otros sectores y en México, de la población económicamente activa (PEA) ocupada masculina, aproximadamente 70\% labora en este sector, lo que significa un mejor ingreso. En la figura I se observa la influencia de cada factor y de cada variable.

En salud, la población femenina derechohabiente representó 51.58\%; además, alcanzaron una esperanza de vida de 75.47 años, superior en 4.64 años a la población masculina. De acuerdo con la figura anterior, es evidente que el factor salud medido a través de la esperanza de vida fue el único aspecto en donde la población femenina superó a la masculina. Es frecuente asociar la longevidad con el mayor uso de servicios de salud y por ello se habla del porcentaje de derechohabientes en la población femenina y masculina, pero es tan recurrente una esperanza de vida femenina mayor a la masculina, se observa hasta en países altamente desarrollados, que una hipótesis adicional de carácter más intrínseco (por ejemplo, una explicación genética o fisiológica) es plausible. En el aspecto educativo, el índice de matriculación

${ }^{5}$ El grado de desigualdad de género se clasifica de la siguiente manera: se dice que en la entidad, o en un municipio, no hay desigualdad o diferencia significativa cuando el porcentaje absoluto de desigualdad entre el IDG y el IDHP respecto del IDHP es menor a $1 \%$, hay diferencia significativa cuando el porcentaje absoluto es mayor o igual a $1 \%$ y menor a 5\%, y por último, hay diferencia altamente significativa cuando el porcentaje absoluto es mayor o igual a $5 \%$. 


\section{Figura I}

Variación en los índices que componen el IDG en hombres y mujeres en el Estado de México, 2000

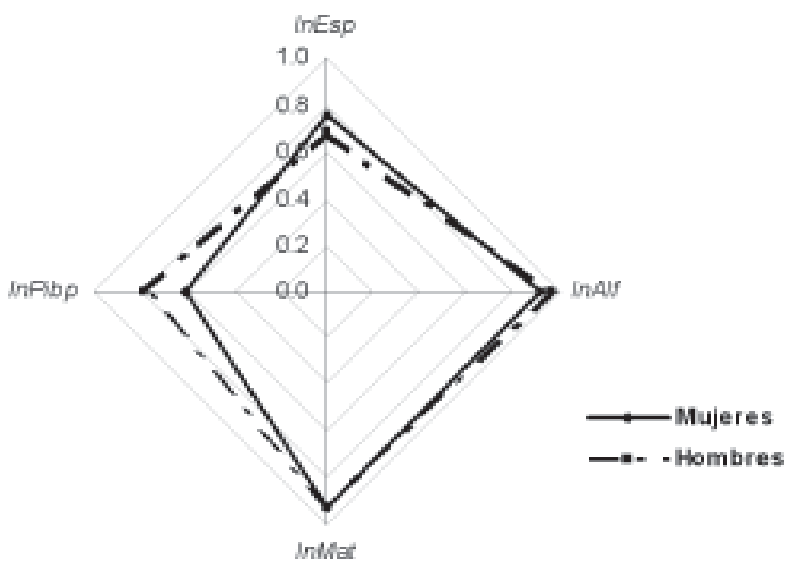

Fuente: Cálculos propios con datos del INEGI. XII Censo 2000, BIE y Simbad.

masculino $\left(\right.$ InMat $\left._{\mathrm{m}}\right)$ fue similar al femenino $\left(\right.$ InMat $\left._{\mathrm{f}}\right)$. En el InAlf se muestra una diferencia significativa de $4.48 \%$ a favor de los hombres, que aunque es menor en apariencia, puede significar un par de décadas para eliminarla. La situación en la alfabetización es otra razón fundamental para el mayor ingreso de los hombres, ya que es de los quince años en adelante cuando las personas se incorporan mayormente al sistema laboral, y es en esta categoría de edad donde los hombres cuentan con mayores oportunidades para acceder al trabajo.

En el año 2000, de los 125 municipios del Estado de México, solamente Ixtapan del Oro, Ayapango y Papalotla no presentaron desigualdad de género $(0.12 \%$ de la población estatal). Los 122 municipios restantes mostraron una desigualdad de género significativa, donde Villa Victoria, Donato Guerra y San Felipe del Progreso tuvieron una desigualdad altamente significativa. Tradicionalmente, en varias comunidades indígenas las mujeres sufren atrasos en sus posibilidades de desarrollo y los municipios citados, no son la excepción, ya que cuentan con una población indígena de 4.97\%, 19.62\% y 41.06\%, respectivamente.

\subsubsection{Variación e inequidad}

Por inequidad también se entiende la desigualdad que se da en el trato a los individuos, de acuerdo con sus necesidades reales, 
independientemente del lugar donde habiten (Rodríguez, 1992). Como se mencionó, se define un índice de inequidad (InQIDHP) como uno menos el índice de Gini (InG $)^{6}$ sobre el IDHP. Una condición de equidad perfecta $(\mathrm{InQ} \mathrm{IDHP}=0)$ no significa que los factores de salud, educación e ingreso se encuentren en las mejores condiciones, sino simplemente indica que están distribuidos equitativamente entre los municipios, aunque estén en un nivel de desarrollo bajo.

En el año 2000, de acuerdo con este indicador, el Estado de México se ubicó en la decimonovena posición con un valor de 0.18584 , el cual señala cierta equidad. Es decir, los habitantes de la entidad presentaban condiciones de DH relativamente similares.

El InQidHP del Estado de México fue 69.59\% mayor que el de Baja California (0.10958), la entidad con menor grado de inequidad en el 2000. En contraste, Oaxaca fue el estado con mayor inequidad (0.43035), de la cual el Estado de México representó solamente el $43.18 \%$. En la figura II se presenta en el eje de las abscisas el porcentaje acumulado de la población del estado y en el eje de las ordenadas el IDHP alcanzado por ésta. La situación de mayor equidad está dada por una línea recta paralela al eje de las abscisas, cuya altura sería el nivel de desarrollo. Mediante el análisis de esta figura, es evidente el mayor grado de inequidad del Estado de México con respecto al de Baja California, pero es más notoria aún la desigualdad entre Oaxaca y el Estado de México.

El grado de inequidad en el estado se debe a varios factores. Uno de los más importantes, como ya se dijo, es el ingreso. El mayor ingreso fue de 9,246.23 dólares PPA registrado en el municipio de Tlalnepantla de Baz, que concentra 5.50\% de la población estatal y cuya economía se basa en la industria y se considera uno de los municipios más industrializados del país. Por tanto, de la PEA ocupada, 64.31\% labora en el sector terciario, 29.99\% en el sector secundario y $5.7 \%$ en el primario. Por otra parte, el ingreso más bajo fue de 2,144.41 dólares PPA registrado en el municipio de Sultepec $(0.21 \%$ de población estatal) donde la prin-

${ }^{6}$ El InG aplicado a la variable de una población mide la distribución de esa variable en la población, si está muy concentrada en pocas clases sociales el índice tiende a uno y si está distribuida equitativamente tiende a cero. Al calcular el InG de la variable IDHP asociada a los municipios de un estado, se requiere que se concentre en el total de la población y que de ahí se tome como medida a uno menos el InG para que un valor cercano a cero dé una condición de equidad en la distribución del IDHP. En este caso, dispersión equivale a una condición de inequidad y concentración es equivalente a equidad, ya que, si los valores municipales del IDHP, dentro de un estado, se concentran alrededor de un determinado punto, significa que todos los valores son más o menos iguales, determinando una situación de equidad (Zamudio et al., 2005). 
Figura II

Variación e inequidad en el Estado de México, 2000

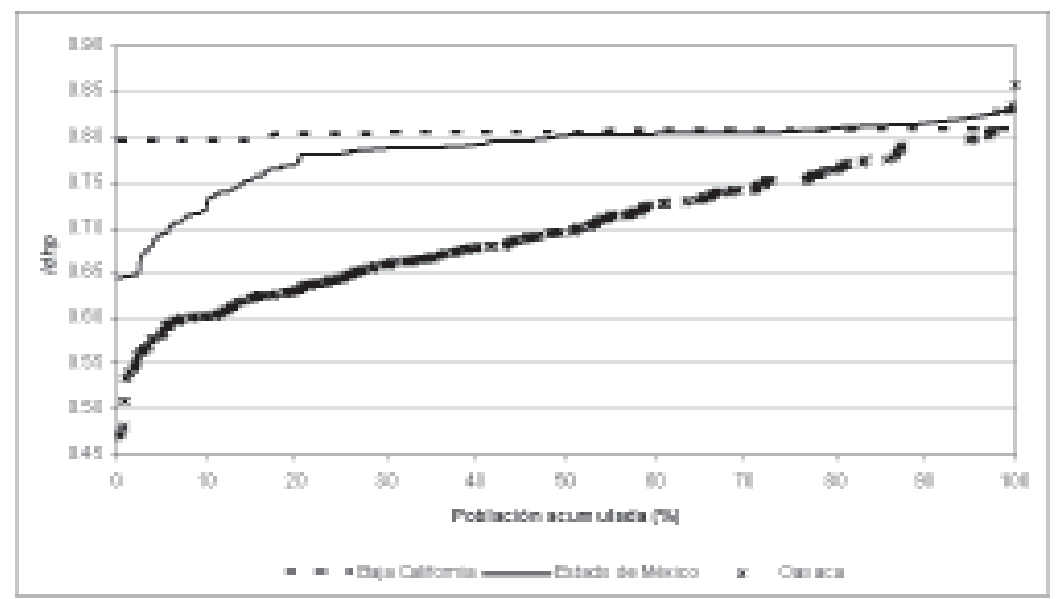

Fuente: Cálculos propios con datos del INEGI. Conteo 1995, XII Censo 2000, BIE y Simbad.

cipal actividad económica es la agricultura y la ganadería, por lo que, de la PEA ocupada, $47.61 \%$ se concentra en el sector primario, $30.91 \%$ en el terciario y $17.38 \%$ en el secundario. El rango de ingresos $(7,101.82$ dólares PPA) indica una dispersión significativa de los mismos en la población mexiquense así como de su acceso a posibilidades de bienestar. La esperanza de vida es otro factor importante que influye en la inequidad de la población del estado, ya que la mayor longevidad (77.2 años) se presentó en el municipio de Jaltenco y la menor (55.2 años) se registró en Atizapán. El rango de 22 años refleja las condiciones disímiles de salud entre los municipios de México, aunque la situación se agudiza en el país, ya que el rango nacional es de alrededor de 30 años. La alfabetización de los adultos también tiene su contribución en las condiciones de desarrollo desigual. Por ejemplo, Sultepec (0.72408), Donato Guerra (0.72473) y San Felipe del Progreso (0.72880) exhiben índices muy lejanos a los de Metepec (0.97151), Cuautitlán Izcalli (0.97446) y Coacalco (0.98487), cuyas diferencias mayores a $24 \%$ son muestra del abandono que sufren ciertos municipios del estado. En cuanto a la alfabetización infantil, se repite lo antes dicho. Un aspecto que se debe considerar en la inequidad en los factores del desarrollo es el número de municipios, ya que los 125 municipios del Estado de México contrastan con los cinco de Baja California, lo cual permite a este último una mejor planeación de las políticas sociales y distribuir de mejor modo los recursos entre sus municipios. 
Oaxaca, con sus 570 municipios, está en el otro extremo de la planeación y distribución de los recursos con una población dispersa que dificulta proporcionar los elementos indispensables para su desarrollo.

\subsubsection{Calidad municipal}

Las curvas de calidad ${ }^{7}$ son una técnica que se utiliza para clasificar a los municipios, estados y países según su eficiencia para traducir el PIBP en salud, educación y servicios públicos, atributos todos esenciales para el desarrollo.

En el año 2000 el Estado de México obtuvo la calidad 12 con un IDHs igual a 0.85673 , ubicándose por arriba del promedio que está entre la calidad 16 y 17, como se muestra en la figura III. Sin embargo, en el quinquenio aquí estudiado el Estado de México no logró traducir con eficiencia el incremento que se tuvo en el PIBP en mejores condiciones de salud, educación y servicios públicos, aun cuando en 1995 tuvo una calidad 11, lo que le significó un IDHS por abajo del esperado (2.95\%). Sin embargo, esta entidad se ubicó en ambos años como la cuarta con mejor calidad estatal, superada en 1995 por Zacatecas, Nayarit y Tlaxcala y en el 2000 por Nayarit, Aguascalientes y Tlaxcala. La explicación del por qué habiendo retrocedido en una posición su clasificación respecto de los demás estados no cambia en el quinquenio, se debe a que al menos 29 de los otros estados tampoco fueron capaces de traducir eficientemente el incremento de su ingreso y, de hecho, lo hicieron con menor eficiencia.

En el año 2000, 92.55\% de los habitantes del estado tenían una calidad mejor que la del país (calidad 20), cuya población se concentraba en 102 municipios. Si se piensa en los contrastes que tiene el Estado de México y que su calidad es superior a la del país, es fácil imaginar la polarización existente entre los habitantes de la República Mexicana. Al interior del estado, 53 municipios $(68.69 \%$ de la población total) tenían una calidad superior a la estatal. El municipio con la mejor calidad municipal (6) en el 2000 fue Coacalco de Berriozábal, con un IDHS de 0.91188 y un ingreso de 8,776.46 dólares PPA. Con este ingreso el municipio era más eficiente en $7.62 \%$ respecto del valor esperado (IDHS

${ }^{7}$ Las curvas de calidad transforman el PIBP de cualquier municipio a un PIBP base donde se comparan todos los municipios. Se construyeron 30 niveles de calidad sobre este PIBP base, la curva de calidad 1 representa la mejor y la curva de calidad 30 representa la peor (Zamudio et al., 2005). 
Figura III

Curvas de calidad y la calidad del Estado de México, 2000

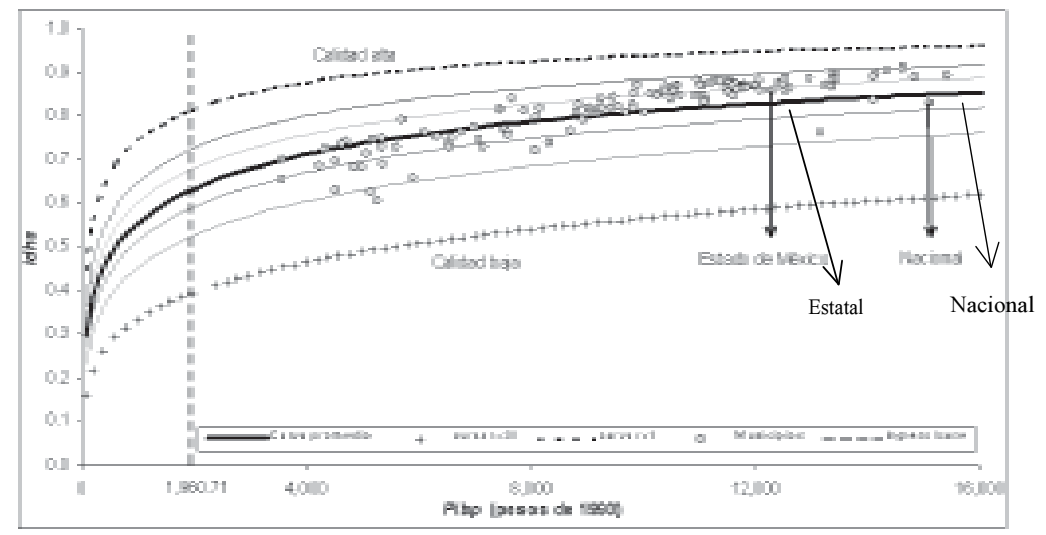

Fuente: Cálculos propios con datos del INEGI. Conteo 1995, XI Censo 1990, XII Censo 2000, BIE y Simbad.

que toma la curva promedio en el punto correspondiente al ingreso del municipio) para transformar este ingreso en desarrollo; le sigue el municipio de Atizapán de Zaragoza con calidad 7 y un IDHS $6.95 \%$ por encima del esperado. En contraste, Villa Victoria presentó la peor calidad (28) con un IDHs de 0.60366 y un PIBP de 3,161.17 dólares PPA. El grado de ineficiencia para este municipio fue de $15.56 \%$.

En general, en toda la República se presentó, un deterioro en la calidad de los municipios; en el Estado de México 92 municipios disminuyeron su calidad, nueve la mantuvieron y sólo los 21 municipios restantes la mejoraron. El que más disminuyó su calidad fue Ecatzingo, de la 7 en 1995 a la 20 en el 2000, presentando una pérdida en calidad de $27.30 \%$. Otros municipios que disminuyeron su calidad fueron: Juchitepec (19.04\%), San Mateo Atenco (18.48\%), Isidro Fabela (16.44\%), Xalatlaco (17.08\%) y Otzoloapan (16.47\%). Los mejores incrementos se ubicaron en Sultepec (17.94\%), Valle de Chalco Solidaridad (10.4\%) y Chalco (10.13\%).

\subsection{Distrito Federal}

\subsubsection{Breve descripción del Distrito Federal}

El Distrito Federal, caracterizado por un perfil geográfico semejante a un corazón, representa el $0.1 \%$ de la superficie nacional. El 
DF colinda al norte, este y oeste con el Estado de México y al sur con Morelos (Agenda, 2000, 2000a). En el 2000, el DF registró una población de 8'605,239 habitantes, 8.83\% de la población total del país, lo que la ubica como la entidad más poblada y con la mayor densidad de población de México; 5,643 habitantes por kilómetro cuadrado. Además, el DF es el centro de poder del país ya que concentra las actividades más importantes en política, economía, comercio, vida social, educación, ciencia y cultura.

La economía del DF es la de un país desarrollado, el sector económico más importante es el de servicios, lejos se encuentra el sector secundario y el sector primario es insignificante. De la PEA ocupada en el año 2000, 75.04\% se encontraba en el sector terciario, $21.15 \%$ en el secundario y el resto en el primario.

\subsubsection{Análisis del desarrollo humano en el Distrito Federal}

\subsubsection{1 Índice de desarrollo humano con PIB per cápita (IDHP)}

En el año 2000, con un IDHP de 0.86258 , su DH fue alto, colocándose como la entidad con mejor DH en la República Mexicana. A escala internacional, el IDHP fue superior con 0.02 unidades al de Argentina y semejante al de Brunei Darussalam, en el sureste asiático (PNUD, 2002: 149), lugar 32 del mundo. El incremento del IDHP en el periodo 1995-2000 fue de 13.25\%. Las dimensiones de salud e ingreso crecieron por arriba del promedio nacional, mientras que la educación se vio afectada, principalmente en la población de 6 a 14 años, donde cuatro de cada mil niños dejaron de tener acceso a la posibilidad de aprender a leer y escribir (cuadro 3). Acerca del aspecto educativo se debe considerar la posición privilegiada del DF frente a las demás entidades federales pero, aun cuando ocupa el primer lugar, 7 de cada 100 niños entre 6 y 14 años y 3 de cada 100 adultos mayores de catorce años no saben leer ni escribir. Significa que 183,083 adultos están en condiciones de extrema precariedad para conseguir empleo y 88,639 niños forman el contingente futuro en esta misma situación, que, aunque en proporción resultan números pequeños, bajo el enfoque humano es difícil aceptar como desarrollo alto.

El avance del IDHP del DF se debe en gran medida al significativo crecimiento económico de la entidad ya que, de 1993 al 2000, la estructura económica experimentó importantes transformaciones. Los cambios más notables son el aumento en la participación de la industria de la transformación y las comunicaciones y trans- 


\section{Cuadro 3 \\ Comparación entre el IDHP y el IDHS (1995-2000) del DF y el país}

\begin{tabular}{|c|c|c|c|c|c|c|}
\hline \multirow[t]{2}{*}{ Indicadores } & \multicolumn{3}{|c|}{ Entidad } & \multicolumn{3}{|c|}{ Nacional } \\
\hline & 1995 & 2000 & $\begin{array}{c}\text { Incremento } \\
(\%)\end{array}$ & o 1995 & $2000 I$ & $\begin{array}{c}\text { Incremento } \\
(\%)\end{array}$ \\
\hline $\begin{array}{l}\text { Índice de esperanza } \\
\text { de vida al nacer }\end{array}$ & 0.69650 & 0.72150 & 8.24 & 0.70967 & 0.73133 & 7.46 \\
\hline (InEsp) & $\begin{array}{l}71.79 \\
\text { Años }\end{array}$ & $\begin{array}{l}73.29 \\
\text { Años }\end{array}$ & & $\begin{array}{l}72.58 \\
\text { Años }\end{array}$ & $\begin{array}{l}73.88 \\
\text { Años }\end{array}$ & \\
\hline $\begin{array}{l}\text { Índice de } \\
\text { matriculación infantil } \\
\text { (InMat) }\end{array}$ & il 0.93365 & 0.92949 & -6.27 & 0.85994 & 0.87280 & 9.18 \\
\hline $\begin{array}{l}\text { Índice de } \\
\text { alfabetización de } \\
\text { adultos (InAlf) }\end{array}$ & 0.96872 & 0.96969 & 3.10 & 0.89258 & 0.90451 & 111.10 \\
\hline producto & 0.87123 & 0.90994 & 30.06 & 0.71931 & 0.75229 & $9 \quad 11.75$ \\
\hline $\begin{array}{l}\text { interno bruto } \\
\text { per cápita }\end{array}$ & $\begin{array}{c}18,492.28 \\
\text { dólares }\end{array}$ & $\begin{array}{r}23,319.08 \\
\text { dólares }\end{array}$ & 26.10 & $\begin{array}{c}7,441.89 \\
\text { dólares }\end{array}$ & $\begin{array}{c}\text { 9,067.94 } \\
\text { dólares }\end{array}$ & $4 \quad 21.85$ \\
\hline (InPIBP) & PPA & PPA & & PPA & PPA & \\
\hline $\mathrm{IDHP}$ & 0.84159 & 0.86258 & 13.25 & 0.77022 & 0.79252 & 9.70 \\
\hline $\begin{array}{l}\text { Índice de agua } \\
\text { (InAgu) }\end{array}$ & 0.97738 & 0.97854 & 5.12 & 0.84580 & 0.87832 & 21.09 \\
\hline $\begin{array}{l}\text { Índice de drenaje } \\
\text { (InDre) }\end{array}$ & 0.97699 & 0.98132 & 18.82 & 0.72401 & 0.76178 & 313.68 \\
\hline $\begin{array}{l}\text { Índice de electricidad } \\
\text { (InEle) }\end{array}$ & d 0.99839 & 0.99548 & -180.75 & 0.92797 & 0.94801 & $1 \quad 27.82$ \\
\hline IDHS & 0.87926 & 0.88763 & 6.93 & 0.80798 & 0.82932 & $2 \quad 11.11$ \\
\hline
\end{tabular}

Fuente: Cálculos propios con datos del INEGI. Conteo 1995, XI Censo 1990, XII Censo 2000, BIE y Simbad.

portes, las cuales incrementaron su aportación en 2.19 y 2.14 puntos porcentuales, respectivamente (Agenda, 2000, 2000b).

El aumento promedio del IDHP nacional fue inferior en $3.55 \%$, no obstante el deterioro de los indicadores educativos del DF. Esta entidad, en comparación con el resto de los estados, presentaba la posición más favorable en la mayoría de los factores a excepción de la salud. El producto per cápita es 2.57 veces mayor al nacional, que si bien no se refleja en el avance quinquenal, sí lo hace en el desarrollo alcanzado. Mientras sólo 70 de cada mil niños en el DF no saben leer ni escribir, el promedio nacional es de 127 y en los adultos hay 30 y 96 por cada mil, respectivamente. En efecto, hay una distancia en las opciones educativas entre la entidad y el país, pero la diferencia en ingreso sugiere que el porcentaje en el DF debería ser mucho menor.

La esperanza de vida, en 1995, se ubicó en la posición 27 y para el año 2000 disminuyó dos posiciones. El DF está entre las 
entidades con menor esperanza de vida (73.29 años) aunque es una de las entidades que sobresale en infraestructura médica y profesional. Sin embargo, no toda la población tiene acceso a los servicios de salud ya que de la población total sólo $51.29 \%$ son derechohabientes. Además influye el medio y tipo de actividades que se desarrollan, ya que la mayoría de los decesos son causados por accidentes automovilísticos y por el alto grado de delincuencia y la consecuente inseguridad. Sobre este aspecto, para el 2000 se observa un contraste relevante entre las delegaciones Coyoacán (75.55 años) y Cuauhtémoc (69.17), una diferencia de 6.38 años (8.45\%). Si se observa la esperanza de vida a los 5, 10, $15 \ldots$ años, la diferencia entre estas delegaciones llega a ser hasta de $10.61 \%$. Hay un contraste más crítico cuando sólo se considera la esperanza de vida al nacer de los hombres: Coyoacán (73.34 años) y Cuauhtémoc (64.34 años), una diferencia de 9 años (12.27\%). Es indudable que las condiciones propiciatorias para una vida larga en la Cuauhtémoc están significativamente vulneradas y una política dirigida a corregir este aspecto se hace improrrogable. Uno de los factores vitales del DH se ve amenazado en el mismo corazón de la ciudad de México, de la gran Tenochtitlan, donde también campea el dominio de los giros negros.

Por otra parte, en el año 2000, las 16 delegaciones presentaron un IDHP que las ubicó con un DH alto; lo que significa que todas las delegaciones, que no quiere decir la población que las habita, tienen las condiciones mínimas necesarias para que sus habitantes accedan a la educación y tengan una vida digna. La longevidad, con un decremento inaceptable, está en espera de estrategias que corrijan este margen. En 1995 sólo la delegación Milpa Alta (0.95\% de la población) presentó un DH medio.

Para el año 2000, las delegaciones que obtuvieron el mejor IDHP fueron, Benito Juárez (0.89268), Coyoacán (0.88462) y Tlalpan (0.87333). Las delegaciones Milpa Alta (0.82471) y Cuauhtémoc $(0.84646)$ obtuvieron los valores más bajos. En Milpa Alta se obtuvo el menor ingreso; la segunda menor esperanza de vida (72 años) y las menores tasas educativas; además, limita con el Estado de México y Morelos y su porcentaje de población indígena es significativo. En la delegación Cuauhtémoc el principal factor que determinó el bajo IDHP fue la esperanza de vida, factor, como se comentó, que se ve sensiblemente dañado.

Se observan diferencias significativas entre algunas delegaciones centrales del DF y otras periféricas. Es decir, Benito Juárez, Coyoacán y Álvaro Obregón, en el centro, presentan niveles más altos de bienestar para sus habitantes que Milpa Alta, Cua- 
jimalpa de Morelos, Tláhuac, Iztapalapa y Gustavo A. Madero en la periferia; en cierta medida por el factor salud.

\subsubsection{2 Índice de desarrollo humano con servicios (IDHS)}

En el 2000, el DF logró un IDHs de 0.88763 (cuadro 3), siendo también en este indicador la entidad con mejor desarrollo en el ámbito nacional. El IDHS nacional fue menor en 5.8\% al índice de la entidad (en el IDHP fue de 7.01\%), lo que indica que el DF, al considerar los servicios en lugar del ingreso, muestra condiciones de desarrollo superiores que el promedio nacional, aunque menores que las exhibidas en ingreso. De acuerdo con los resultados del cuadro 3, los cambios presentados en los servicios hablan de un esfuerzo dirigido al drenaje, principalmente en las localidades periféricas del oriente donde existen muchos asentamientos irregulares. El exagerado retroceso en el servicio de energía eléctrica se debe a que en 1995 sólo entre uno y dos habitantes de cada mil no contaban con éste, el cual ascendió en 2000 a entre cuatro y cinco. Aun con lo anterior, el DF presentó el mejor índice de energía del país: en promedio, 52 de cada mil carecen del servicio. Respecto a la cobertura de agua, sobre la cual se manifiestan las mayores preocupaciones por parte de la población y sus gobernantes, con el incremento logrado en el quinquenio la entidad conservó la segunda posición. Sin lugar a dudas, los esfuerzos por cubrir las necesidades de agua del centro del país son legítimas y están cabalmente justificadas por las carencias que de ésta se tiene en las colonias periféricas, no obstante, si se piensa en el lugar que ocupa el DF en la cobertura del servicio, es fácil inferir la situación en la que se encuentran millones de habitantes de la nación. En general, la mayoría de los habitantes del DF contaba con los tres servicios públicos, sólo 2\% carecía de alguno de ellos.

De los índices del cuadro 3, a excepción del de la esperanza de vida cuyo valor es muy bajo respecto de los demás, las características del desarrollo en el DF son favorables para sus habitantes. Es innegable que las opciones para una vida prolongada en el DF están disminuidas y con ello el DH de la entidad. Si bien es cierto que se conocen los efectos colaterales de vivir en ciudades grandes, no deja de sorprender que el deterioro sea tan marcado.

En 1995 y 2000, las 16 delegaciones presentaron un IDHS alto. Las que tuvieron el mejor en el año 2000 fueron Benito Juárez (0.90574) y Coyoacán (0.90493), ubicadas en la parte central de la ciudad de México. La cobertura de los servicios en estas dele- 
gaciones es casi total. Por otro lado, Milpa Alta (0.85145), Cuauhtémoc $(0.86784)$ y Xochimilco $(0.87596)$ obtuvieron los menores IDHS. Dos terceras partes del territorio de Milpa Alta es montañoso con declives y bosques y solamente $16.5 \%$ del suelo es urbano, esto contribuyó para obtener el menor índice.

En algunas delegaciones el número de viviendas particulares disminuyó entre 1990 y el 2000, como fue el caso de Cuauhtémoc y Miguel Hidalgo, con tasas de $-0.6 \%$ y $-0.3 \%$, respectivamente. Estas delegaciones céntricas están expuestas al proceso de cambio de uso de suelo, de habitacional a comercial y de servicios, lo que las convierte en expulsoras de población. En otro grupo de delegaciones, las periféricas (Tláhuac, Milpa Alta, Tlalpan, Cuajimalpa de Morelos, Iztapalapa y parte de Xochimilco), se observa un incremento en el número de viviendas y de habitantes, con frecuentes asentamientos irregulares en zonas de alto riesgo donde las familias carecen principalmente de servicios públicos y pavimentación (GDF, 2000), carencia manifiesta en el IDHS.

\subsubsection{3 Índice de desarrollo humano relativo al género (IDG)}

En 1995 el Distrito Federal obtuvo un IDG de 0.83062, mientras que en el 2000 fue de 0.85598 , alto en ambos años; pero fue inferior al IDHP, donde mostró desigualdad en las opciones de desarrollo para hombres y mujeres. La diferencia en 1995 fue de $1.30 \%$, la cual se redujo a $0.76 \%$ para el 2000 . Este descenso fue suficiente para que en el 2000 no presentara diferencia significativa de género y se colocara como la mayor potenciadora de las opciones para las mujeres.

Al final del periodo el ingreso femenino fue de 14,857.73 dólares PPA, y el masculino de 32,571.46 dólares PPA, valores que según el Banco Mundial son altos. Aunque el ingreso femenino es inferior al masculino ( 0.4562 veces), la diferencia es menor a la que existía en 1995 (0.356 veces) y donde se observa la incorporación de la mujer a la vida económica en los últimos años. A pesar de la marcada diferencia de ingresos, los niveles en que se encuentran están entre los que, ya no contribuyen en mucha medida en incrementos al DH. De la PEA ocupada total del DF, $38.74 \%$ eran mujeres que laboraban principalmente en el sector terciario y, de la población económicamente inactiva femenina, $55.7 \%$ se dedicaba a los quehaceres domésticos y $22.6 \%$ estudiaba. La alfabetización infantil femenina (0.93117) fue superior a la masculina (0.92785), mientras que la adulta masculina $(0.98207)$ fue mayor a la femenina $(0.95885)$. Aun con estas di- 


\section{Figura IV}

Variación en los índices que componen el IDG en hombres y mujeres en el DF, 2000

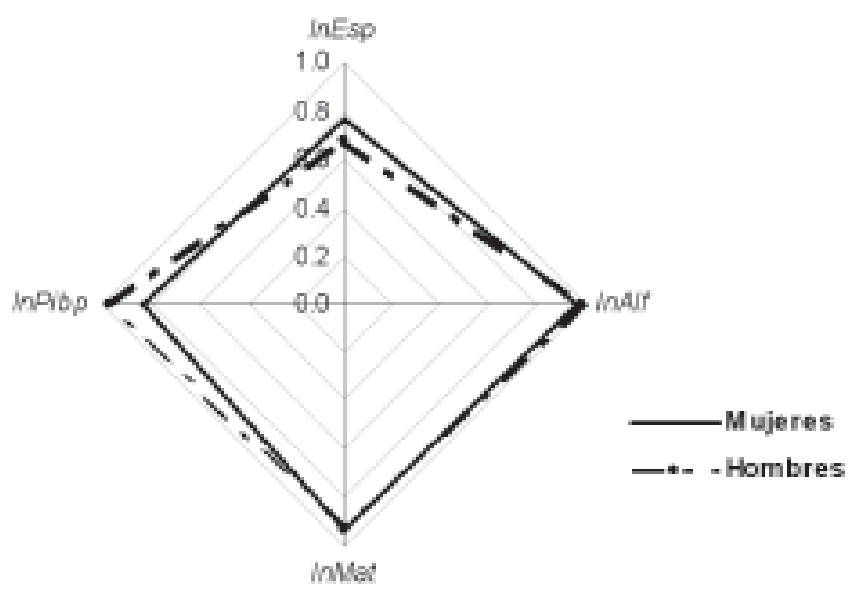

Fuente: Cálculos propios con datos del INEGI. XII Censo 2000, BIE y Simbad.

ferencias, los niveles educativos de ambos géneros son comparables (figura IV); es decir, tienen oportunidades educativas semejantes. Con respecto a la esperanza de vida, en promedio las mujeres (75.65 años) viven cinco años más que los hombres. De acuerdo con lo anterior, la diferencia de ingreso, a favor de los hombres, se compensa con la diferencia en esperanza de vida, a favor de las mujeres, por lo que el IDG dista poco del IDHP.

Por otra parte, de las 16 delegaciones, 13 no presentaron desigualdad significativa de género, mientras que en Cuajimalpa de Morelos (1.13\%), Milpa Alta (1.1\%) y Tláhuac (1.06\%) sí la hubo, lugares donde residía el $6.40 \%$ de la población total del DF. Además, es importante mencionar que Milpa Alta (4.53\%), Cuajimalpa de Morelos (1.52\%) y Tláhuac (1.51\%) tienen los porcentajes más altos de población indígena de la entidad (INEGI, 2000b), la cual es un componente que, de modo recurrente, está asociada a diferencias en desarrollo, no sólo en el país sino en todo el mundo.

\subsubsection{Variación e inequidad}

Al final del periodo estudiado, el Distrito Federal obtuvo un índice de inequidad del IDHP (InQIDHP) de 0.1629, el cual la hace una entidad relativamente equitativa. Baja California (0.1096) 
fue la entidad más equitativa del país, en la doceava posición a escala nacional, por arriba de Jalisco $(0.1634)$ y estados sobre todo del sur, pero ligeramente abajo de Nuevo León (0.1625).

Por otra parte, la inequidad del DF representó 37.97\% de la inequidad de Oaxaca (0.43035), que fue el estado peor calificado en este rubro. En la figura $\mathrm{v}$ se muestra la distribución del IDHP sobre la población en el DF y los estados referenciales del mínimo y máximo índice de inequidad. Las pequeñas pendientes que se observan en el primer decil y en los últimos dos de la curva correspondiente al DF, hacen la diferencia en el exceso de inequidad que tiene esta entidad respecto a la de Baja California. Por supuesto, la mayor altura de la curva del DF señala su mayor DH. El contraste de ambas entidades con Oaxaca indica la asociación entre bajo desarrollo e inequidad, una asociación perniciosa y recurrente donde la carencia de opciones de desarrollo (manifiesta en la baja altura de su curva) se traslada a un trato desigual en el otorgamiento de las mismas entre las partes del estado (manifiesto en la pendiente pronunciada de su curva).

\section{Figura $v$}

\section{Variación e inequidad en el Distrito Federal, 2000}

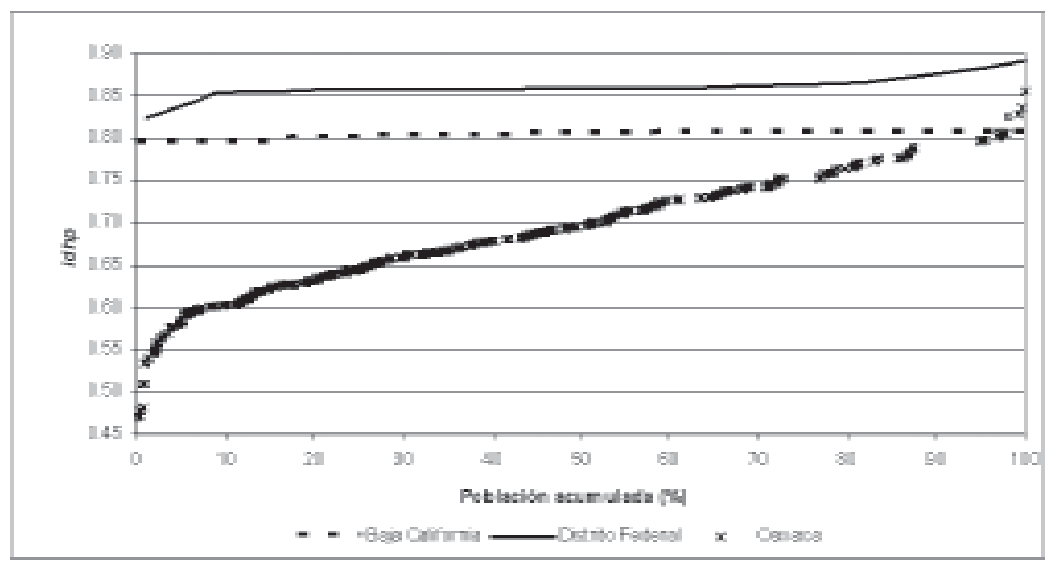

Fuente: Elaboración propia con datos del INEGI. Conteo 1995, XII Censo 2000, BIE y Simbad.

Por lo anterior se puede decir que los habitantes del DF presentan condiciones similares de DH. El máximo IDHP (0.89268), registrado en la delegación Benito Juárez (4.2\% de la población), se compara con el mínimo (0.82471) de Milpa Alta (1.12\% de la 
población). La diferencia entre ambos índices (0.06797) no resulta crítica si se considera que se da en la zona de alto desarrollo.

El bajo grado de inequidad que presenta el DF se debe en primera instancia al ingreso. El mejor ingreso (PIBP) fue de 30,526.14 dólares PPA, y se obtuvo en la delegación Benito Juárez donde la población ocupada se distribuye de la siguiente manera: $84.67 \%$ labora en el sector terciario, $12.13 \%$ en el secundario y $0.15 \%$ en el primario. El menor ingreso fue de $15,942.75$ dólares PPA, registrado en Milpa Alta. En esta delegación, la población ocupada participó con $14.25 \%$ en el sector primario, $21.02 \%$ en el secundario y $63.53 \%$ en el terciario. Las diferencias en ambas delegaciones, se presentan en los niveles no críticos para el DH. En el aspecto educativo, todas las delegaciones mostraron tasas similares, lo que refleja una situación de equidad educativa. La máxima tasa de educación fue de $97.96 \%$ y la mínima de $92.77 \%$. En salud, su esperanza de vida en general es muy baja con respecto a otras entidades, por ejemplo Oaxaca, lo que señala la dimensión más crítica en la entidad y su pequeño efecto en el IDG.

\subsubsection{Calidad de las delegaciones}

De acuerdo con el criterio de calidad utilizado, en el año 2000 el DF fue ineficaz para traducir el ingreso en desarrollo, por lo que obtuvo el lugar 22. La calidad de las delegaciones y la de todo el DF se muestra en la figura VI. En este rubro el DF se encontraba por debajo del promedio, que se localiza entre las curvas $16 \mathrm{y}$ 17. En el periodo, este indicador registró un retroceso de $5.5 \%$, al descender de la calidad 21 a la 22. Cuatro delegaciones que concentraban $45.92 \%$ de la población alcanzaron una mejor calidad que la obtenida por la entidad, nueve $(42.85 \%$ de la población) tenían una calidad igual a la de la entidad y el resto de la población presentó una calidad inferior.

En general todas las delegaciones tienen una calidad baja, lo cual indica que se esperarían mejores condiciones de salud, educación y servicios respecto del valor del ingreso. En esta circunstancia, es claro el efecto de las tasas decrecientes de desarrollo a medida que aumenta el ingreso. Por lo mismo, la capacidad para traducir el ingreso en desarrollo es similar en todas las delegaciones y su calidad se encuentra entre la 21 y la 25 . La delegación Cuauhtémoc, con un ingreso de 25,199.96 dólares PPA y un IDHS de 0.86794 , obtuvo la calidad más baja (25). Fue ineficaz en 
Figura VI

Curvas de calidad y la calidad del Distrito Federal, 2000

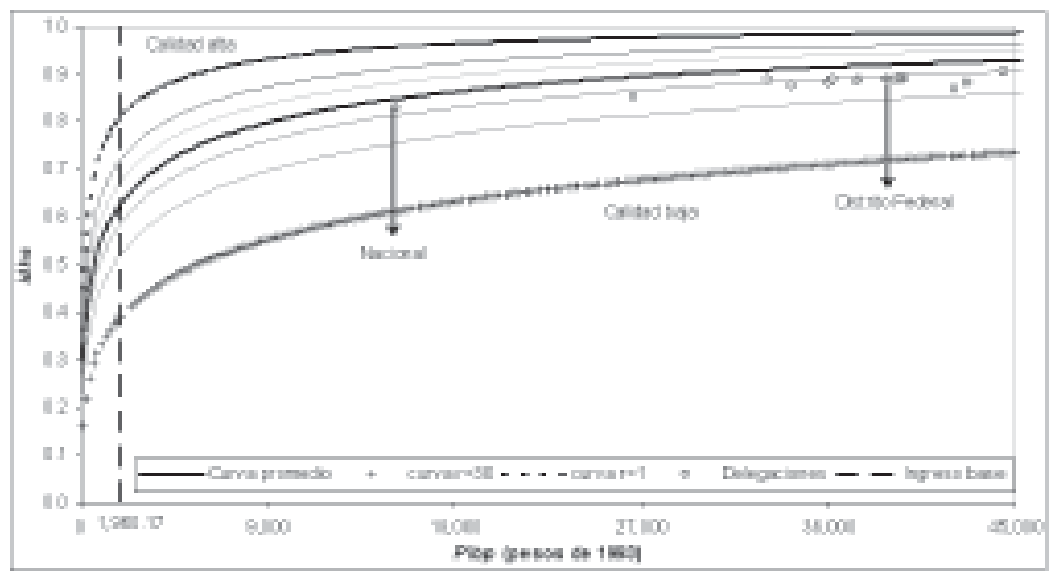

Fuente: Cálculos propios con datos de INEGI. Conteo 1995, XII Censo 2000, BIE y Simbad.

$6.2 \%$ con respecto al valor esperado (IDHS sobre la curva promedio en el punto correspondiente al ingreso de la delegación).

Por otra parte, 12 delegaciones redujeron su calidad, tres se mantuvieron con la misma y solamente Miguel Hidalgo la incrementó en 3.35\%, pasando de la calidad 25 a la 24 durante el periodo. Las delegaciones que más disminuyeron su calidad fueron: Milpa Alta, Tláhuac, Cuajimalpa de Morelos, Magdalena Contreras e Iztapalapa. En la primera, la calidad retrocedió $12.23 \%$, en 1995 tenía calidad 18 y en el 2000 obtuvo la 23. Tláhuac disminuyó 8.67\%, pasando de la calidad 16 a la 20. Finalmente, en Cuajimalpa de Morelos (19 a 22), Magdalena Contreras (19 a 22) e Iztapalapa (18 a 21), la calidad retrocedió alrededor de $7.27 \%$.

\section{Conclusiones}

Los cuatro componentes esenciales del DH son: equidad, sustentabilidad, productividad y empoderamiento (Cazés, 2001).

La inequidad, como diferencias injustas, es la constante que lacera el DH; dentro de sus múltiples caras, la que se distingue invariablemente es el ingreso, sea indirecto como el PIBP, sea directo como el familiar. Otras inequidades consecuentes se tienen en aspectos relevantes del DH. Así, la enorme desigualdad entre los ingresos del Estado de México y el DF; las diferencias abismales en los índices educativos entre los municipios del Estado de México, mayores a 24\%; y la distribución desigual en la 
esperanza de vida entre las delegaciones del DF exhiben el rostro de inequidad que amenaza las aspiraciones del DH. El número de años que llevará corregir estas disparidades augura un lapso prolongado, si no se modifican los criterios de política económica y social hasta ahora determinados. La diferencia en los ingresos de estas entidades se extendió durante el quinquenio estudiado, de 3.165 veces a 3.213 (en dólares PPA), lo que cancela cualquier posibilidad de convergencia en el DH entre ellas por la correlación de este factor con los demás. La desigual distribución de la riqueza en el mundo se reconoce como la principal causa, producto de ver a las personas como medios y no como fines del desarrollo, que detiene la igualdad que debiera prevalecer entre los seres humanos, de ahí su estrecha vinculación con la inequidad. Respecto de la forma en que se distribuye el desarrollo dentro de estas entidades, en ambas se tiene una mejor distribución que la del promedio nacional, aunque el Estado de México se encuentra siete posiciones por debajo del DF. Es muy clara la inequidad en el desarrollo que se observa a lo largo de los 125 municipios de México en comparación con la de las 16 delegaciones del DF. Si en lugar de enfocarnos en los municipios se considera la población que está en condiciones de inequidad, las cosas no se muestran tan desfavorables para el Estado de México, ya que los municipios que exhiben desarrollos muy bajos contienen poblaciones pequeñas. Por el contrario, las condiciones de desarrollo de los habitantes del DF son más homogéneas, a pesar de las diferencias.

La sustentabilidad contiene la visión filosófica del derecho de las generaciones siguientes a disfrutar, por lo menos, del bienestar presente en su relación con el medio ambiente y con todo lo que abarca lo social y lo cultural. Sin embargo, esto no significa sostener los actuales niveles de pobreza y privación humanas. El Estado de México, si no comparte con el DF el desarrollo en lo que respecta a educación, servicios e ingreso, sí comparte el nivel desfavorable en salud, expresada en la esperanza de vida que en el Estado de México y el DF ocupan los lugares 27 y 25 de la clasificación nacional, respectivamente, comparables con la de Chiapas y Oaxaca. No es sustentable mantener, en un estado de privación, las condiciones que alargan la vida como se muestra en las entidades aquí estudiadas. En el caso del DF, se cuenta con un ingreso que podría compensar la pérdida de años de vida, si se puede ver así, pero en el Estado de México no se tiene ni siquiera esta posibilidad. En términos de DH, como expresión de bienestar, resulta muy difícil equiparar los factores que lo com- 
ponen pero, de acuerdo con la estimación de Naciones Unidas, así se hace por razones prácticas de medición y comparabilidad. Aun con este sesgo, el DF comparte condiciones desfavorables con el Estado de México para una vida larga pero no así los beneficios del ingreso, ampliando con ello las divergencias en el DH. Este esquema de crecimiento, que no desarrollo, no es sustentable y reclama ser corregido. En otras palabras, no se puede mantener ningún tipo de condición desfavorable injusta entre los seres humanos como las condiciones de salud para el Estado de México y el DF, respecto al promedio del país, y la del ingreso del Estado de México respecto al DF.

La productividad, como expresión de crecimiento que olvida el componente humano del desarrollo y que en el mejor de los casos ve al hombre como capital, se finca en maximizar el trabajo y las ganancias. La diferencia de valor del IDHP entre el Estado de México y el DF exhibe una historia de este desarrollo basado en el crecimiento del ingreso, a pesar de ser entidades vecinas que comparten obligadamente una infraestructura enorme de servicios en salud, educación y vivienda, además de comunicaciones, transporte, comercio, etcétera. La productividad, como expresión del DH, tendría que medirse en términos de lo que la gente obtiene a partir de lo que produce, en otra forma de eficacia de la que ha operado hasta ahora. En esta dirección habría que hablar de la eficacia con la que el ingreso se traduce a algún aspecto del DH y de ello da cuenta el concepto de calidad introducido en la relación entre el IDHS y el PIBP. Debe observarse que esta medida ya toma en cuenta los rendimientos decrecientes del ingreso sobre el $\mathrm{DH}$, de modo que expresa la eficacia con la que se traduce el ingreso en el DH de los municipios del país. La capacidad para transformar el ingreso en DH se observa más eficiente en el Estado de México que en el DF. Con un ingreso menor a un tercio, ubica varios de los atributos del desarrollo, principalmente educación y salud, y en menor proporción los servicios públicos, en condiciones equiparables con los del DF. La calidad de México se clasifica diez posiciones por encima de la del DF, y de hecho, éste ocupa el penúltimo lugar de la clasificación. El significado de lo anterior es que el ingreso per cápita que tienen los habitantes del DF (de acuerdo con las estimaciones del INEGI) indica que su grado de DH debería ser mayor.

El empoderamiento en la escala humana se refiere al poder vivir, desarrollarse y gozar de bienestar y, en efecto, para ello se debe ceder ese poder a la gente en opciones que les permitan lo referido. No es el poder que se ejerce para imponer la voluntad de 
un grupo a otro, sino el que la gente tenga opciones como reciprocidad por su trabajo y que se ha ejercido erróneamente por otros. Además, los cambios ocurridos en este aspecto a través de la historia muestran la riqueza humana cuando se les permite a las personas oprimidas hacer uso de este poder. Pares de grupos en estas circunstancias son hombres y mujeres, indígenas y no indígenas, rurales y urbanos, etcétera, siendo el primer par uno de los más sentidos y al que se han sumado muchos en su mejoramiento. En los informes de DH, mundiales o específicos de un país, se informa de diferencias en las oportunidades que tienen hombres y mujeres para desarrollar sus capacidades, aunque estas diferencias son menores a las que se presentan en las oportunidades para hacer uso de las capacidades desarrolladas, las cuales se miden de modo diferente. En México se observa lo mismo y por supuesto hay distancias considerables entre las entidades estudiadas. El Estado de México terminó el quinquenio con una desigualdad significativa de $1.42 \%$, en comparación con la del DF de sólo $0.76 \%$, la más pequeña de las 32 entidades del país. Mientras que en el Estado de México hay 122 municipios (99.88\% de la población) en una condición de desigualdad importante, en el DF sólo tres delegaciones (6.4\% de la población) están en esta situación. Las oportunidades entre hombres y mujeres para desarrollarse en el Estado de México son significativamente diferentes en casi la totalidad de la población, siendo favorables para los hombres en todos los municipios del estado. El empoderamiento necesario en las mujeres, a pesar de la mejoría obtenida de 1995 a 2000, aún requiere la atención especial de las políticas sociales que atenúen las disparidades, permitiendo que las mujeres tengan mejores oportunidades de educarse y de tener una vida digna y plena. Se debe observar que estos dos grupos no son los únicos en contraste de empoderamiento en el Estado de México, los grupos indígenas se encuentran muy aislados del desarrollo, potenciando el empobrecimiento de las mujeres.

Con lo aquí expuesto, entre el Estado de México y el DF, así como al interior de ellos, las dimensiones del DH se observan sensiblemente alejadas de sus condiciones deseables. La constante inequidad en los atributos del DH, en situaciones que no pueden ser sostenidas, con una productividad ajena a la visión humana y con un empoderamiento que asume lentamente su papel, muestran la dificultad para lograr el DH de estas entidades y su lejana vecindad. En el mismo centro del país queda mucho por igualar. 


\section{Bibliografía}

Anand, Sudhir y Amartya Sen (2000), "The Income Component of the Human Development Index", Journal of Human Development, 1(1), Carfax Publishing, Londres, pp. 83-106.

Agenda 2000 (2000a), Estadísticas, Aspectos Geográficos, Ubicación Geográfica, Gobierno del Distrito Federal, en www.df.gob.mx/agenda2000/ageograficos/1_1.html, 10 de noviembre de 2005 .

Agenda 2000 (2000b), Estadísticas, Indicadores Económicos, Producto Interno Bruto, Gobierno del Distrito Federal, en www.df.gob.mx/agenda2000/ieconomicos/12_20.html, 10 de noviembre de 2005.

Aregional (2001), Geografía, historia y monografía, Indicadores Económicos, México, en www.aregional.com/documentos $/$ pdf $/$ mexico.pdf? $\mathrm{c}=12 \& \mathrm{~s}=77 \& \mathrm{x}=1174,29 \mathrm{de}$ marzo de 2004.

Bojorges-Sosa, José Ambrosio (2000), Uso de estadísticos de orden para construir curvas de indice de sitio, tesis de maestría en ciencias, División de Ciencias Forestales, Universidad Autónoma Chapingo, México, 117 pp.

Cazés-Menache, Daniel (2001), "Prólogo al Informe del Desarrollo Humano en México", en Francisco J. Zamudio S. et al., Primer Informe sobre Desarrollo Humano de México 1995, México, Universidad Autónoma Chapingo-Centro de Desarrollo Humano de Guanajuato, A. C., 196 pp.

Desai, Meghnad (1991), "Human development: Concepts and measurement", European Economic Review, 35, Países Bajos, pp. 350-357.

Gobierno del Distrito Federal (GDF) (2000), Secretarías, Programas, Programa de Población del Distrito Federal 20012006, Población y desarrollo, Gobierno del Distrito Federal, en www.df.gob.mx/secretarias/social/copodf/ prog3.html\#pobdes, 12 de noviembre de 2005. 
(INEGI) Instituto Nacional de Estadística, Geografía e Informática (2000a), México, Información Estadística, Estadística por proyecto, XII Censo General de Población y Vivienda 2000, Base de Datos, Tabulados Básicos, en www.inegi.gob.mx/ est/default.asp?c=704, 13 de octubre de 2005.

(INEGI) Instituto Nacional de Estadística, Geografía e Informática (2000b), Distrito Federal, Información Estadística, Estadística por proyecto, XII Censo General de Población y Vivienda 2000, Base de Datos, Tabulados Básicos, en www.inegi.gob.mx/est/default.asp?c $=704,11$ de diciembre de 2005.

(Inafed) Instituto Nacional para el Federalismo y el Desarrollo Municipal (2001), Servicios de Información, Enciclopedia de los municipios de México, México, Medio físico, Inafed, en www.e-local.gob.mx/wb2/ELOCAL/EMM_ mexico, 13 de octubre de 2005.

López-Arellano, Oliva (2005), “Desigualdad, pobreza, inequidad y exclusión. Diferencias conceptuales e implicaciones para las políticas públicas", en www.paho.org/Spanish/DPM/ SHD/HP//hp-xi-taller04-pres-lopez-arellano.pdf, 30 de junio de 2005.

Medina, Fernando (2001), "Consideraciones sobre el índice de Gini para medir la concentración del ingreso", Serie Estudios Estadísticos y Prospectivos, División de Estadística y Proyecciones Económicas, CEPAL, Santiago de Chile, pp. 373-345.

Molina, Emiro (2005), "La medición de la equidad: marco conceptual", Red Venezolana de Conocimiento Económico, en http://www.redeconomia.org.ve/documentos/emolina. doc, 20 de junio de 2005.

Pérez-Miranda, Mónica Gladis (2001), Desarrollo humano en México: 1995, tesis profesional, División de Ciencias Forestales, México, Universidad Autónoma Chapingo, 190 pp.

(PNUD) Programa de las Naciones Unidas para el Desarrollo (1990), Informe sobre Desarrollo Humano 1990, Nueva York, Oxford University Press, 337 pp. 
(PNUD) Programa de las Naciones Unidas para el Desarrollo (1995), Human Development Report 1995, United Nations Development Programme, Nueva York, Oxford University Press, 143 pp.

(PNUD) Programa de las Naciones Unidas para el Desarrollo (2001), Human Development Report 2001, United Nations Development Programme, Nueva York, Oxford University Press, 264 pp.

(PNUD) Programa de las Naciones Unidas para el Desarrollo (2002), Human Development Report 2002, United Nations Development Programme, Nueva York, Oxford University Press, 277 pp.

Ramírez-Magaña, Alejandro (1999), "Índice de desarrollo humano del estado de Guanajuato", Revista del Centro de Desarrollo Humano de Guanajuato, A. C., 3, México, pp. 9-28.

Rodríguez-Hernández, Francisco (1992), Atención a la salud y desigualdad regional: distribución de los recursos para la atención de la salud en México, México, Consejo Nacional de Ciencia y Tecnología-Universidad Nacional Autónoma de México, Centro Regional de Investigaciones Multidisciplinarias, Cuernavaca, 98 pp.

Zamudio-Sánchez, Francisco José (1997), Curvas de indice de sitio usando estadísticos de orden, Memoria Técnica, Departamento de Estadística, Matemática y Cómputo, División de Ciencias Forestales, México, Universidad Autónoma Chapingo, México.

Zamudio-Sánchez, Francisco José, José Luis Romo Lozano y Domingo Rosas Ríos (2005), "Análisis comparativo 19952000 del desarrollo humano de los estados de Colima, Jalisco y Nayarit", Espiral: Estudios sobre Estado y Sociedad, 34, México, pp. 95-124.

Recibido: 14 de diciembre de 2005. Reenviado: 26 de septiembre de 2006. Liberado: 8 de enero de 2007. 
Francisco José Zamudio Sánchez. Es doctor en filosofía por la Universidad Estatal de Iowa, asimismo realizó estudios de Maestría en Ciencias en el Colegio de Postgraduados (СР) y de Licenciatura en la Universidad Autónoma Chapingo (UACH). Actualmente es investigador nivel I en el Sistema Nacional de Investigadores (SNI) y es Director del Programa Nacional de Investigación Sobre Desarrollo Humano en México del Departamento de Estadística, Matemática y Cómputo de la UACH. Sus líneas de investigación actuales son: medidas del desarrollo humano, de lo rural y metodología estadística en poblaciones humanas. Entre sus publicaciones destacan: "Optimización financiera para establecer un sistema agroforestal: costo-beneficio, precios aleatorios, distintos escenarios y externalidades", Revista Fitotecnia Mexicana, 28 (4), pp. 311-318, 2005; "Análisis comparativo del desarrollo humano en los estados de Chihuahua y Sinaloa, 1995-2000", Región y Sociedad, Revista de El Colegio de Sonora XVIII (35), 2006; Informe sobre desarrollo bumano en México: análisis comparativo en el estado de Chiapas (Guerrero, Hidalgo, México, Michoacán, Puebla, Oaxaca y Veracruz) 19952000, Centro de Estudios para el Desarrollo Rural Sustentable y la Soberanía Alimentaria, Cámara de Diputados, 2006 (ocho monografías).

Alejandro Corona-Ambriz. Es maestro en ciencias por el Colegio de Postgraduados, Montecillos, México. Asimismo, realizó sus estudios de licenciatura en la Universidad Autónoma Chapingo (UACH). Actualmente es profesor-investigador de tiempo completo del Departamento de Estadística, Matemática y Cómputo de la División de Ciencias Forestales, UACH. Es colaborador del Programa de Desarrollo Humano de la UACH. Sus líneas de investigación actuales son: análisis del desarrollo humano en México a escala municipal y estatal. Es colaborador en ocho publicaciones: Informe sobre desarrollo humano en México, análisis comparativo en el estado de Chiapas (Guerrero, Hidalgo, México, Michoacán, Oaxaca, Puebla y Veracruz).

Rubén González Mireles. Es licenciado por el Departamento de Estadística, Matemática y Computo de la División de Ciencias Forestales en la Universidad Autónoma Chapingo. Actualmente labora en el Instituto de Información e Investigación Geográfica, Estadística y Catastral del Estado de México, dentro del Departamento de Estadística Económica. Participa en la revisión, validación e integración de la información económica para la elabo- 
ración de documentos estadísticos como: "Agenda Estadística Básica del Estado de México”, "Agenda Estadística Básica Municipal”, "Producto Interno Bruto Municipal", "Producto Interno Bruto Estatal y Nacional”, entre otros. Asimismo participó en la investigación y cálculo de los niveles de pobreza en el Estado de México. Colaboró en su institución académica en el proyecto de investigación sobre desarrollo humano en México, del cual elaboro la tesis denominada "Segundo informe sobre desarrollo humano del Estado de México y el Distrito Federal: análisis comparativo 1995-2000”. 